\title{
Managing Iterative Projects More Effectively: Theories, Techniques and Heuristics for $\mathrm{HCl}$ Practitioners
}

\author{
John Long \\ University College London \\ Gower Street \\ London \\ WC1H OAP \\ j.long@ucl.ac.uk
}

\author{
Steve Cummaford \\ IMG Media \\ McCormack House \\ London \\ W4 2TH
}

steve.cummaford@imgworld.com

\begin{abstract}
Most HCI specialists are involved, in one way or another, with iterative project management (IPM), as opposed to HCI, on a day-to-day basis. However, few specialists have any systematic training or exposure to IPM. Further, market pressures highlight the importance of HCI iterative and adaptive planning and development to meet changing conditions, associated with novel technology and customer change. This tutorial is intended to fill these gaps. IPM is characterised in terms of its theory, its methods and heuristics to support its practice. Exercises and mini-practicals support the integration of $\mathrm{HCI}$ into the heuristics, methods and theory of IPM. In the light of our recent experience, participants' IPM effectiveness, as either managers or as team members, is expected to increase as a result.
\end{abstract}

\section{INTRODUCTION}

Most HCI system development takes place within the context of the project, whether embedded, cash point, fun, web site or complex systems. Such projects are conducted by project managers and carried out by project teams. Most projects are iterative. As a result, HCI specialists are involved with iterative project management (IPM) on a day-to-day basis, including the iteration of the HCI/User-Centred Design (UCD) contributions, for which they are responsible. However, very few such specialists have any systematic training or exposure to IPM. Further, the increasing pressure of the introduction of novel technology and of the market place, constraining budgets, while shortening deadlines, ensures there is an ever-greater need to manage projects iteratively and to plan adaptively, consistent with both IPM and HCI/UCD constraints. Otherwise, the potential for IPM error will increase too. Changing plans, including those of UCD, within a fixed budget, has become a routine IPM requirement; but one, which is all-too-often carried out ineffectively. This tutorial supports both managers and team members in meeting this requirement, as well as filling the training/educational gap.

\section{LEARNING OBJECTIVES}

The learning objects for the participants are threefold:

(C) John Long and Steve Cummaford, 2007

Published by the British Computer Society

Volume 2 Proceedings of the 21st BCS HCI Group Conference

HCI 2007, Lancaster University, 3-7 September 2007

Devina Ramduny-Ellis \& Dorothy Rachovides (Editors)
- To understand the scope; theory; and practice of IPM, as they relate to HCI.

- To become acquainted with, and selectively to practise, UCD methods, in relation to IPM.

- $\quad$ To become familiar with IPM guidance, in the form of heuristics, which they can integrate into IPM and HCI methods.

Following tutorial attendance. Participants should be able:

- To follow up further their interest in IPM via the literature, the web and other sources.

- To make IPM issues explicit in their own UCD activities and to suggest approaches to them.

- To contribute to IPM best practice, within their own HCI projects.

- To become a more effective HCI member of the IPM team.

\section{PARTICIPANTS}

The tutorial is of interest to anyone involved in, or indeed concerned by, HCI/UCD, including: human factors and software engineers; project managers; usability specialists; user experience architects; designers; graphic artists; web services teams; project sponsors; marketers; financers etc. The prerequisites for the tutorial are either that participants have some experience of IPM projects, either as managers or as HCI/UCD team members, or that they have an interest in HCI and IPM, directly or indirectly, that they would like to develop further.

\section{OVERVIEW BY SESSION}

\subsection{IPM theory}

The question of what is IPM, as it relates to HCI/UCD, is answered by proposals, concerning: its definition (What is iterative? What is IPM?); its concerns (resources; effort; people/teams; and risks); its discipline: (research; tools; casestudies) and practice (iterative; incremental; evolutionary; and adaptive); and the requirement for IPM, as it relates to HCI/UCD (common managers' problems and common team members' problems). IPM knowledge is reviewed in terms of: Waterfall problems; research; standards; experts; and business cases. IPM practice is characterised by: its types (risk-driven; client-driven;); its methods (planning; development; and Agile); and its development cycle (pre-production; production; maintenance; and evaluation), as concerns HCI/UCD practice. 


\subsection{IPM method}

IPM planning and development methods are reviewed. A web site development method is selected for particular address and is used to illustrate the nature of IPM and HCI/UCD practice. However, its general aspects are emphasised. The major phases and stages of the method are described and illustrated. These comprise: pre-production - project clarification; solution definitions; and project specification; production - content; design; construction; testing, launch and hand-over; maintenance; and evaluation. HCI and UCD practice and methods are situated with respect to the IPM method.

\subsection{IPM practice}

Heuristics have been culled from a wide range of different sources, both published and experienced. The heuristics are organised around the following topics: project management: planning; iterating; environment; requirements; and testing. All topics are illustrated and exemplified. Participants practise mapping the heuristics (3) to the methods (2) in the light of theory (1), as they concern HCI/UCD practice.

\section{REVIEW}

The tutorial is well suited to presentation at HCI 2007.The level is introductory to intermediary. It is accessible to participants, newly involved or interested in IPM and so, introductory. The tutorial provides definitions of IPM, surveys IPM knowledge, and reviews the need for IPM, as it relates to UCD. It is also intended to improve IPM practice of participants with some experience of IPM and so, intermediary. It addresses issues such as: contingency planning; overlapping project activities; multi-team and multi-site working; and risk assessment. It is not intended for experienced IPM managers, managers of very large and complex projects or team members, operating within mature and well-structured practice.
The purpose of the tutorial is to increase awareness of IPM and to contribute to IPM and UCD best practice in participants' future projects. The significance of the tutorial is to fill a gap for both HCI project team members and managers. As such, it is entirely suitable for HCI 2007, fitting well with the theme of 'exploring new frontiers'.

\subsection{ABOUT THE PRESENTERS}

John Long initially worked for Shell Oil International, as a manager, before joining the Medical Research Council's Applied Psychology Unit, Cambridge, as a researcher in Human Factors and HCI. He moved to UCL and led a research group for 20 years. He is currently Emeritus Professor of Cognitive Engineering at UCL. He has authored and coauthored over 200 publications and has acted as an external consultant to many companies, government agencies and universities. He has extensive experience in managing large HCI projects. He was awarded the Outstanding Educator Award by the IEA. He has wide interests, including: usability engineering; applied psychology; office and high street systems; command and control systems; distributed work; and telecommunications-supported work.

Steve Cummaford worked as a Research Fellow in the Department of Psychology, investigating the design of effective e-commerce interfaces, before being appointed Lecturer in HCI, University College London (UCL). He continues to be active in teaching and research. He was a founding partner of Amberlight Partners, a leading HCI consultancy based in London, designing and evaluating websites for clients including Autotrader, AOL, Ask Jeeves, MSN and Yell. Steve is now at IMG Media, where he manages the design and production of websites and mobile applications for clients including Manchester United, FIFA, The Open Championship, O2, Vodafone and Miss World. 